\title{
Uma cartilha orientadora para projetos de intervenção de design em comunidades produtivas artesanais
} A guideline booklet for design intervention projects in crafts productive communities

\author{
Renata Garcia Wanderley, Cecília da Rocha Pêssoa \& Camila Brito Vasconcelos
}

cartilha, diretrizes, intervenção, design

\begin{abstract}
A desvalorização social e cultural do artesanato demanda sua adaptação a um novo cenário de mercado. Seu trabalho em conjunto com o design vem sendo a estratégia empregada por meio de programas de intervenção de design. Contudo, esse processo não tem gerado resultados duradouros. Assim sendo, essa pesquisa buscou construir diretrizes orientadoras estruturadas numa cartilha. Para tanto desenvolveu uma pesquisa analítico-qualitativa com conversa com 100 artesãos de 16 comunidades sobre os programas de intervenção nos quais eles participaram. Como resultado foram apresentados os pontos negativos e positivos dos programas segundo os artesãos. Essa problemática envolveu (1) 0 projeto em si; (2) sua execução; (3) conteúdo trabalhado e (4) participantes. A participação ativa dos artesãos desde a elaboração do projeto a execução das oficinas como oficineiros se destacam como fundamentais. Foram enfatizados também como importantes conteúdos e distribuição de carga horária das oficinas contexualizados com a comunidade. Além desses resultados diretos, também puderam ser concluídos algumas características da comunidade que facilitam e dificultam a execução e manutenção das ações dos projetos de intervenção. A presença de uma liderança ativa (natural ou construída) e a compreensão da necessidade e o interesse em mudanças são as principais facilitadores. Como entrave destacam-se o imediatismo financeiro e a baixo autoestima dos artesãos. Diante dessas informações, algumas diretrizes orientadoras podem ser identificadas.
\end{abstract}

booklet, quidelines, intervetion, design

The social and cultural devaluation of the handicraft demands its adaptation to a new market scenario. His work in conjunction with design has been the strategy employed through design intervention programs. However, this process has not produced lasting results. Therefore, this research sought to construct guidelines orientated in a booklet. For that, he developed an analytical-qualitative research with talk with 100 artisans from 16 communities about the intervention programs in which they participated. As a result the negative and positive points of the programs according to the craftsmen were presented. This problem involved (1) the project itself; (2) its execution; (3) content worked and (4) participants. The active participation of the craftsmen since the elaboration of the project the execution of the workshops as office workers stand out as fundamental. They were also emphasized as important contents and distribution of the workload of the workshops contextualized with the community. In addition to these direct results, it was also possible to conclude some community characteristics that facilitate and hinder the execution and maintenance of the actions of intervention projects. The presence of active leadership (natural or built) and the understanding of the need and interest in change are the main facilitators. As an obstacle, the financial immediacy and the low self-esteem of the artisans stand out. Faced with this information, some guidelines can be identified.

\section{Introdução}

No Brasil, o artesanato vem perdendo sua existência social e sua força cultural devido à falta de identidade dessas ações como expressão da comunidade, de qualidade técnica, de divulgação, de valorização pessoal e coletiva. Diante dessa problemática e compreendendo as práticas culturais como dinâmicas e mutáveis, as atividades artesanais devem se adaptar a um novo panorama. Esse cenário é um mercado com concorrência com artefatos digitais e produtos industrializados com características muito diferentes dos artefatos artesanais. Com isso, o artesanato precisa consolidar seu conceito e suas características diferenciadoras para ser escolhido por esse seu conceito. Como apresenta Wanderley (2015) o artesanato é tanto

Anais do 9 CIDI e 9 CONGIC

Luciane Maria Fadel, Carla Spinillo, Anderson Horta, Cristina Portugal (orgs.)

Sociedade Brasileira de Design da Informação - SBDI

Belo Horizonte | Brasil | 2019

ISBN 978-85-212-1728-2
Proceedings of the 9th CIDI and 9th CONGIC

Luciane Maria Fadel, Carla Spinillo, Anderson Horta, Cristina Portugal (orgs.)

Sociedade Brasileira de Design da Informação - SBDI Belo Horizonte | Brazil | 2019

ISBN 978-85-212-1728-2 
um produto como um processo e envolve 03 características fundamentais: (1) predominância de manipulação manual; (2) resultado direto da energia do artesão com identidade de autor; (3) uma representatividade cultural.

Como estratégia de ação, a participação do design em comunidades artesanais se apresenta com uma possibilidade eficaz de orientação dessas mudanças. Esse trabalho entre design e artesanato vem ocorrendo através de programas de intervenção como o Programa do Artesanato Brasileiro, o Artesol, o Programa SEBRAE de Artesanato e o Imaginário.

Entretanto, como aponta Wanderley (2018) ainda são identificados problemas na consolidação dessa interação entre artesanato e design, com os programas, apresentando-se com o problema de pesquisa desse estudo. Conhecimentos perdidos, ações não continuadas ou não empregadas, retrocessos de processos são exemplos observados quando a atuação dos programas é finalizada.

Embora os interventores entendam com profundidade os programas e tenham experiência nesses processos, não fazem parte do cenário real da atividade produtiva e dos artesãos. Sua análise ocorre numa perspectiva de fora para dentro. A discussão com os artesãos validaria e complementaria essa diagnose do ponto de vista interno.

Assim sendo, essa pesquisa objetivou a construção de diretrizes orientadoras para programas de intervenção de design em comunidade produtivas artesanais. Buscou também (a) Identificação dos pontos positivos e negativos de alguns programas de intervenção, (b) a estruturação do processo de interação dos conhecimentos do artesanato e do design e (c) a estruturação de uma cartilha.

Para tanto, foi desenvolvida uma pesquisa analítica-qualitativa. Construiu-se o conhecimento pela análise crítica das informações (críticas e elogios) dos objetos de estudo (dos artesãos). E preocupou-se com a existência e o significado dos fatos em si e não como sua periodicidade, trabalhando as informações independente de sua frequência de ocorrência e do tamanho da amostragem.

Envolveu o método de abordagem indutivo ao trabalhar casos particulares (comunidades) para conclusões gerais (principais problemas e aspectos importante para programas de intervenções em design). No contexto total se qualifica com o método de procedimento estruturalista ao buscar pela integração de múltiplos conhecimentos o desenvolvimento de uma estrutura de orientação (as diretrizes e a cartilha) para representar e trabalhar o objeto de estudo (a integração do artesanato e o design).

Como técnica de pesquisa trabalhou a entrevista semiestruturada em forma de conversa informal com ênfase na avaliação por parte dos artesãos dos projetos de intervenção nos quais participaram. Ela ocorreu em ambiente coletivo da comunidade e envolveu a participação de 100 artesãos de 16 comunidades diferentes. A conversa foi mediada pelos pesquisadores da pesquisa com a introdução alguns questionamentos bases.

\section{Fundamentação teórica}

Em função do volume de informações coletados na pesquisa do projeto artesanato compartilhado o design da informação foi de fundamental importância para compilação da informações e principalmente para torna-las compreensível de forma eficiente e clara para o público geral.

Uma vez que, segundo Pettersson (2012), o design da informação objetiva a clareza na comunicação, foi indispensável organizar os relatos de artesãos, conclusões dos pesquisadores e diretrizes orientadoras de forma clara, deixando claro detalhes processuais, pontos problemáticos e facilitadores, aspectos positivos e negativos, dentre outras informações necessárias de maneira ordenada e compreensível.

As informações foram organizadas em tópicos, separadas por tipos e numeradas. Preparar o conteúdo e sua apresentação foi um desafio no qual o design da informação foi a principal 
ferramenta, considerando apontamentos de Horn (1999) sobre o preparo das informações para uso eficaz e eficiente das mesmas pelos humanos.

Mas além da organização das informações, representa-las de maneira visual para uma comunicação eficiente e eficaz também foi desafiador e inspirou a confecção da cartilha que será apresentada mais adiante neste artigo. As demandas visuais que deveriam nortear a cartilha foram definidas com a divisão das informações, estabelecendo os principais grupos das diretrizes e representando-os com ícones, a fim de facilitar a compreensão.

“...o IIID (International Institute for Information Design) contextualiza o design da informação partindo dos conceitos de informação e design, sendo a informação definida como resultado do processamento, manipulação e organização de dados de uma maneira que agregue conhecimento ao receptor. Já o design é apresentado como o ato de identificar um problema e o esforço intelectual criativo do emissor, que apresenta soluções por meio de desenhos e planos que incluem esquemas e especificações para serem absorvidas pelo receptor. Por fim, o design da informação é a definição, planejamento e elaboração do conteúdo de uma mensagem e os ambientes em que são apresentados, com a intenção de satisfazer as necessidades de informação dos destinatários." (Scariot \& Schlemmer, 2012, p. 03).

Em função dessa necessidade de apresentação visual das informações da pesquisa por meio de uma cartilha que a tornasse acessível para as instituições que promovem projetos de intervenção, para designers e artesãos, além do público geral, a cartilha foi planejada para versão impressa e digital, já que segundo Baer (2009) em todos os meios é necessária a eficácia das informações.

O cuidado com a maneira como a informação é apresentada é essencial para que os resultados da pesquisa sejam produtivos, que possam ser utilizados, revisados e consultados sempre que necessário, "....as mensagens devem ser cuidadosamente projetadas, produzidas e distribuídas para, mais tarde, serem corretamente interpretadas e compreendidas pela maioria dos indivíduos dentro da audiência pretendida." (Dick, Gonçalves \& Vitorino, 2017, p. 03).

Sem uma apresentação adequada as informações tornam-se apenas um acúmulo de dados, não correspondendo a real valor da pesquisa que pode ser melhor reconhecido se as informações são facilmente identificadas e compreendidas. Estabelecer a comunicação eficaz entre os principais personagens interessados no conteúdo da pesquisa apresentado na cartilha é o objetivo maior.

\section{A pesquisa}

$\mathrm{Na}$ conversa/entrevista com os artesãos, eles apresentaram 29 problemas e 28 pontos positivos gerais dos programas de intervenção nos quais participaram. Essa problemática girou em torno do (1) projeto em si, em relação a elaboração, temporalidade, pessoas e conteúdo e das (2) ações do projeto sobre igualmente conteúdo, temporalidade e pessoas mas também didática e estrutura.

\section{Pontos negativos dos projetos}

1. Projeto pronto - sem a participação do grupo;

2. Projeto curto;

3. Projeto descontinuado;

4. Projeto inacabado;

5. Projeto restrito a capacitações;

6. Pouca ação de promoção;

7. Pouca ação de comercialização;

8. Ações muito espaçadas;

9. Oficina restritasa orientação/a correção;

10. Aulas muito teóricas com pouca prática;

11. Não consolidação das técnicas ensinadas;

12. Conteúdo das oficinas não adequado ao grupo (muito restrito ou muito variado); 
13. Cursos com distribuição de carga horária não adequada ao grupo (consideradas curtas ou longas);

14. Sem estímulo e capacitação para a criação (como desenhos prontos);

15. Pouca variedade de cursos;

16. Proposta de produtos não diferenciados;

17. Proposta de atividades e produtos cópias;

18. Produtos sem identidade pessoal ou com a comunidade;

19. Materiais inadequados (caros, difíceis de conseguir, ou não identificaçãocom o artesão);

20. Técnicas sem identidade individual ou com a comunidade;

21. Descontextualização: técnica não adaptável ao material e ao equipamento trabalhado pela comunidade;

22. Oficineiro não apto para o desenvolvimento da técnica;

23. Oficineiro não apto a orientação, principalmente para trabalhar erros;

\section{Pontos positivos dos projetos}

1. Projetos longos;

2. Contato com os interventores constante e fácil;

3. Contato fácil com os responsáveis pelo projeto;

4. Doação de equipamentos e materiais;

5. Horário e dia das oficinas acessíveis;

6. Adequação da carga horária a disponibilidade dos artesãos;

7. Participação de artesãos como instrutores;

8. Linguagem acessível por parte dos professores;

9. Professores qualificados e ativos;

10. Professores pacientes;

11. Metodologia de ensino eficiente;

12. Desenvolvimento de melhoria dos produtos já desenvolvidos;

13. Entendimento por parte dos artesãos da necessidade de novos produtos;

14. Entendimento por parte dos artesãos da necessidade de desenhos mais contextualizados;

15. Entendimento por parte dos artesãos de controle de qualidade e gestão;

16. Entendimento por parte dos artesãos da necessidade de cuidar de seus resíduos;

17. Visitas a casos de sucesso;

18. Visitas técnicas no mercado;

19. Introdução de novos temas;

20. Trabalho com material reciclável;

21. Adaptação de técnicas;

22. Identificação do ramo de produto;

23. Oficina decores;

24. Aulas de vendas;

25. Aulas de inglês;

26. Todos os artesãos passarem por todas as etapas do projeto;

27. Entendimento teórico e prático de todo o processo de cada artesão participante;

28. Promoção dos produtos em feiras;

29. Apoio psicológico quando necessário.

Além desses resultados diretos, também puderam ser concluídos algumas características da comunidade que facilitam e dificultam a execução e manutenção das ações dos projetos de intervenção. Elas não são definitivas mas tem influência no andamento e consolidação dos projetos. São bem variadas mas percorrem os domínios, pessoas, estrutura, produtos e processos.

\section{Facilidades da comunidade para o desenvolvimento de projetos de intervenção}

1. Interesse e amor pela atividade;

2. Liderança definida;

3. Líder com caráter colaborativo, inciativa e curiosidade grande; 
4. Líder com habilidade crítica e criatividade;

5. Líder com habilidade de ensino;

6. Líder com formação;

7. Espírito colaborativo;

8. Dedicação exclusiva;

9. Disposição a mudanças;

10. Disposição a aprender;

11. Disposição em investir financeiramente;

12. Espaçode produção específico e "próprio";

13. Espaçode comercialização específico e "próprio";

14. Técnica tradicional consolidada;

15. Técnica fácil de repassar;

16. Artesãos capacitados na técnica;

17. Variadas atividades produtivas;

18. Material disponível na comunidade,

19. Consciência da necessidade do artesanato da comunidade ter uma identidade;

20. Identidade de produto.

\section{Facilidades da comunidade para o desenvolvimento de projetos de intervenção}

1. Dependência de projetos em execução;

2. Baixa autoestima;

3. Imediatismo Financeiro;

4. Insegurança;

5. Sem liderança;

6. Líder como patrões;

7. Sem iniciativa;

8. Não tem uma matéria-prima típica;

9. Sem uma técnica consolidada; 1

10. Produto sem identidade;

11. Grande dependência das Associações para realização das ações;

12. Sem consciência do que querem (além de ganhar dinheiro);

13. Dedicação não exclusiva

Com esses dois grupos de saberes trabalhados na pesquisa foram elaboradas as diretrizes.

\section{As Diretrizes}

Um processo de mudança efetiva em qualquer comunidade só acontece se envolver o compartilhamento de pensamentos, atitudes e emoções entre todos os participantes. Este processo gera a sensação de pertencimento, cria comprometimento e estimula a coletividade.

Esse compartilhamento acontece com o planejamento (identificação de informações), execução (compartilhamento de informações) e avalição (reflexão da informações). Por tanto, o programa igualmente deve se estruturar nessas três ações, tornando-as suas fases básicas.

Também duas qualidades principais são fundamentais para os programas: (a) colaboração, participação efetiva de todos em todo o processo e (b) flexibilidade, possibilidade de sua adaptação à realidade concreta de cada comunidade e cada artesão. Além dessas duas bases, quatro parâmetros são atuantes para a estruturação, execução e efetivação representativa dos resultados dos programas: atores, processos, conteúdos e resultados.

Os atores se compõem pelas pessoas envolvidas no programa

como os artesãos, os designers, entre outros. São identificados os meios de envolvê-las e as formas adequadas delas participarem. Como objetivo principal, busca-se o envolvimento emocional, a colaboração e a autonomia. 
Os processos representam as ações a serem desenvolvidas. São apontadas suas características necessárias no domínio temporal, espacial e humano. As ações contextualizadas e identitárias são representativas e aceitas.

O conteúdo envolve os conhecimentos e temas importantes ao artesanato e a sua produção. São indicadas as principais ideias a serem trabalhadas. Foca ao mesmo tempo na identidade da atividade e do grupo como na geração de conhecimentos e competências.

Os resultados são as soluções concretas para problemas bases de comunidades artesanais. São indicados algumas mudanças, decisões e produtos necessários a todas. Busca diretamente a sustentabilidade produtiva com a satisfação dos atores.

\section{Atores}

1. Viabilizar a colaboração total dos artesãos, principalmente na elaboração do projeto;

2. Promover acessibilidade aos integrantes do projeto pelos artesãos participantes, tanto durante a execução como em qualquer momento;

3. Envolver oficineiros não só orientando (mandando fazer) mas sabendo e fazendo também;

4. Implantar a participação dos artesãos como instrutores com o acompanhamento de integrantes do projeto;

5. Instrutores e alunos trabalhando de forma horizontal, não hierarquizada e com compartilhamento recíproco de conhecimentos;

6. Liberar a autonomia de decisões para os artesãos.

\section{Processo}

1. Implantar projetos longos, progressivos e abrangentes em diversas áreas (como design, administração, comunicação, entre outras);

2. Desenvolver ações constantes e sem grande intervalo de tempo entre elas;

3. Instaurar formação continuada e sistemática;

4. Realizar visitas técnicas para conhecer realidades bem-sucedidas;

5. Desenvolver capacitação através de oficinas;

6. Realizar oficinas com atividades sequenciais;

7. Realizar oficinas não só para orientação: primeiro trabalhar um produto novo com o ensino do fazer e só depois orientar o melhoramento dos produtos já desenvolvidos;

8. Realizar oficinas com espaçamento de tempo para não parar a produção por muito tempo;

9. Realizar oficinas com diversos exercícios, inclusive extra sala para assimilar e praticar os conhecimentos.

\section{Conteúdo}

1. Trabalhar a conscientização de qualidade, de identidade, de preocupação com resíduos;

2. Ter como oficinas bases:

- Criatividade e desenvolvimento de novos produtos,

- Linguagem gráfica (cor, textura, forma, entre outros elementos estéticos-simbólicos),

- identidade,

- formação de preços,

- gestão,

- empreendedorismo,

- qualidade,

- desenvolvimento de alto autoestima e independência;

3. Aproveitar matéria-prima disponível e identitária da comunidade;

4. Explorar as técnicas já desenvolvidas na comunidade;

5. Trabalhar com técnicas identitárias da comunidade; 
6. Trabalhar sistemas de preço adequados às realidades produtivas e de mercado daquele tipo de artesanato e não apenas como base em horas trabalhadas;

7. Trabalhar com processos e estratégias de vendas;

8. Incluir nas oficinas a importância de cada mudança sugerida (em ações e produtos) e conhecimentos trabalhados.

\section{Resultados}

1. Qualificar os produtos já desenvolvidos;

2. Qualificar os processos necessários à atividade;

3. Qualificar a estrutura (espaço, móveis, maquinário e ferramenta) da atividade;

4. Desenvolver produtos novos e diferentes / inovadores;

5. Criar a identidade visual do grupo e compostos promocionais (como catálogos e folders);

6. Estabelecer parcerias;

7. Definir sistema de preço;

8. Implantar técnicas de comercialização

9. Construir estratégias de promoção;

10. Estabelecer táticas para cultivar clientes (brindes, produtos personalizados e etc);

11. Trabalhar com coleções - novas propostas a cada ano,

12. Apontar/identificar/preparar um líder;

13. Identificar o mercado, o público alvo principal e o secundário do tipo de artesanato.

\section{A Cartilha}

Todas as informações coletadas e concluídas na pesquisa foram organizadas em uma cartilha chamada Artesanato Compartilhado (figura 1). Esse projeto foi definido pois a cartilha seria a forma mais eficaz de apresentar os conhecimentos construídos e de esses conhecimentos serem aplicados em contextos reais.

Figura 1: A cartilha (usado com a permissão de Wanderley).
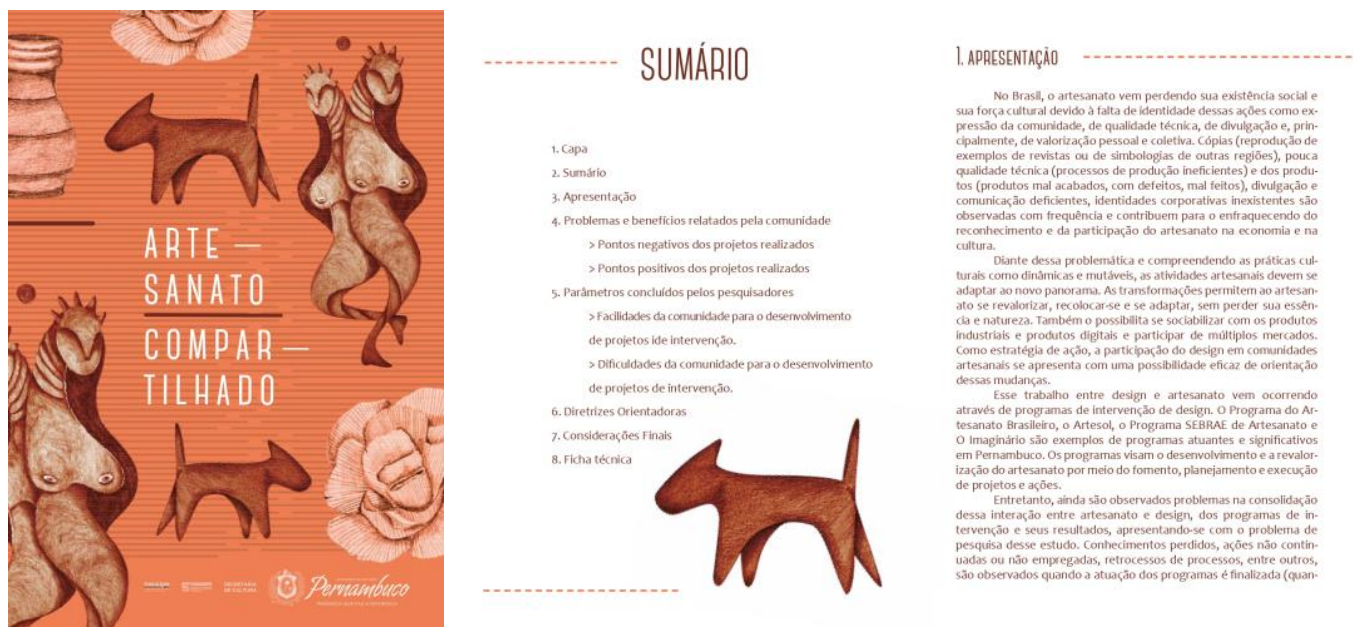

A organização da cartilha foi complexa com muitas informações independentes e ao mesmo tempo complementares tendo de ser apresentadas textualmente (o que é desinteressante $e$ cansativo). Assim sendo, foi iniciado a organização das informações em blocos e sublocos, expressos textualmente e quando possível esquematizados em infográficos.

A primeira informação trabalhada foi o conceito e características do artesanato. Ela foi esquematizada num infográfico (figura 2) que demonstra a ligação entre as características do artesanato e os domínios sociais. 
Figura 2: Esquematização do conceito de artesanato (usado com a permissão de Wanderley).

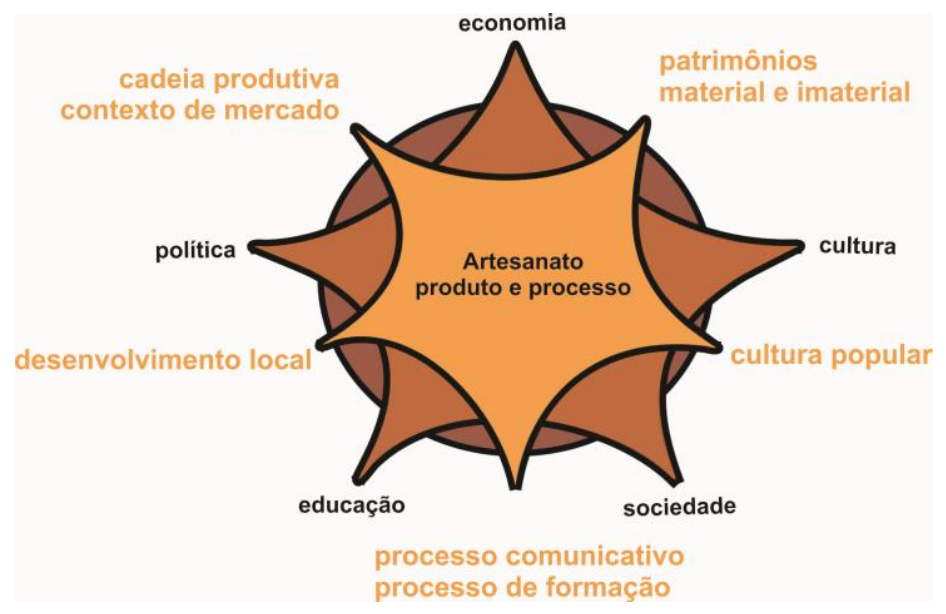

O primeiro grupo de informações trabalhado foi a apresentação da contexto de atuação da pesquisa com suas problemáticas (do artesanato e dos programas) e suas soluções (intervenção do design e cartilha). Todo o conteúdo foi verbalizado textualmente (introdução desse artigo) e também esquematizado na figura 3.

Figura 2: Esquematização do contexto da pesquisa (usado com a permissão de Wanderley).

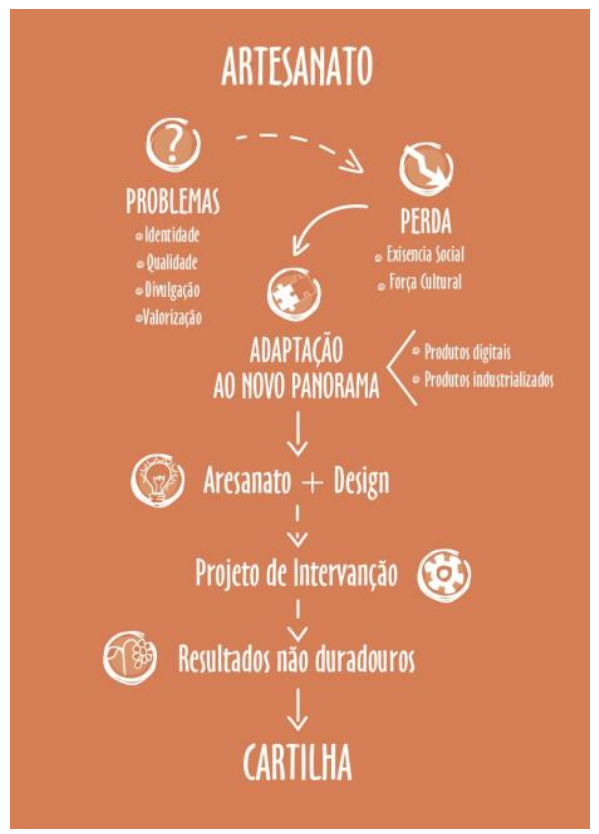

O resultado da pesquisa (a pesquisa e as diretrizes desse artigo) foi organizado em 03 grupos de saberes: (1) Diagnóstico dos Projetos Relatados pela Comunidade (2) Parâmetros Influenciadores concluídos pelos pesquisadores e (3) Diretrizes Orientadoras. Esse divisão aconteceu pois a conversa (entrevista informal coletiva) proporcionou (a) a identificação de problemas e benefícios dos projetos implementados segundo seus artesãos participantes (diagnóstico) mas também (b) a conclusão de algumas características da comunidade facilitadoras e dificultadoras para o desenvolvimento de projetos de intervenção (parâmetros) que juntos construíram (c) as diretrizes.

O diagnóstico é compostos pelos problemas e sucessos apontados pelos artesãos participantes dos diversos projetos desenvolvidos. Os parâmetros se constitui com as facilidades e dificuldades características das comunidades que influenciam positiva e 
negativamente no desenvolvimentos do projetos identificados pelas pesquisadoras. Todos os esses conteúdos foram apresentados por modo verbal com esquematização apenas da estrutura de organização.

Por fim as diretrizes representam as principais instruções bases concluídas a partir do diagnóstico e dos parâmetros para a elaboração, execução e manutenção de projetos de intervenção em design em comunidades produtivas artesanais. Elas foram estruturadas em 04 pilares: (1) atores, (2) processos, (3) conteúdo e (4) Resultado. Os atores representam as pessoas integrantes do projeto, englobando os interventores (representantes do projeto: como os designers, entre outros), os artesãos e seus parceiros. Processo se compõe pelas ações propostas e/ou desenvolvidas com o projeto. O conteúdo se estabelece como os temas e os conhecimentos e temas importantes ao artesanato e a sua produção trabalhados no projetos. $\mathrm{E}$ os resultados são os benefícios atingidos como o projeto, as soluções concretas para problemas bases de comunidades artesanais. Seu conteúdo interno foi expresso textualmente mas sua estrutura foi esquematizada na figura 4.

Figura 4: Esquematização das diretrizes (usado com a permissão de Wanderley).

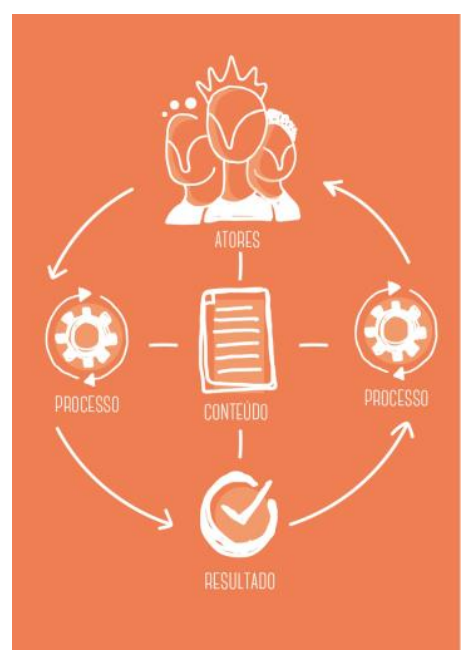

\section{Considerações finais}

A cartilha Artesanato Compartilhado ainda é teórica, não tendo sido empregada em situações reais e nem utilizada por participantes de projetos. Contudo, mesmo não sendo comprovada sua eficácia, esta se estabelece pois o conteúdo da cartilha foi construído com informações derivadas de contextos reais e diretos de comunidades artesanais. Além disso, a estruturação da cartilha foi desenvolvida com base nos princípios do design da informação.

A metodologia empregada demonstrou ser eficaz. A origem das informações envolvendo sujeitos diretamente relacionados com o tema, os artesãos participantes de projetos de intervenção de design, fornece informações contextualizadas. A quantidade de artesãos e comunidades envolvidas foi significativa e com características diversas permitindo maior abrangência e variabilidade de informações, Também a análise e conclusão das informações ocorrendo por meio de pesquisadores experientes na área de intervenção constroem diretrizes fundamentadas.

Contudo, a experimentação da cartilha na prática é uma exigência. Além disso, deve ser complementada com dados coletados de outros contextos como o teórico (outras pesquisas sobre projetos de intervenção), pesquisa analítica das principais programas de intervenção e a visão de interventores. Essas ações permitirão confirmar, ajustar ou modificar algumas informações.

Enfim, observa-se que os próprios programas de intervenção e seus projetos podem ser bases para a auto avaliação e a avaliação externa de sua capacidade de transformação. 
Também, seus participantes, mais precisamente os artesãos, fornecem informações importantes a nível estrutural, humano e técnico para a avaliação e construção de projetos de intervenção em design.

\section{Agradecimento}

Agradecimento ao Governo do Estado de Pernambuco / Fundarpe pelo apoio financeiro ao projeto Artesanato Compartilhado e UFPE pelo apoio humano.

\section{Referências}

Baer, K. (2009). Information Design Workbook: graphics, approaches, solutions, and inspiration +30 case studies. Beverly: Rockport Publishers.

Dick, M. E., Gonçalves B. S., \& Vitorino E. V. (2017). Design da informação e competência em informação: relações possíveis. Revista Brasileira de Design da Informação, 17(1), pp. $1-13$.

Horn, R. (1999). Information Design. In Jacobsen, R., Information Design, pp. 15- 33. Cambridge, MA: MIT Press.

Pettersson, R. (2012). It Depends: ID - Principles and guidelines. 4. ed. Tullinge, Sweden.

Scariot, C., \& Schlemmer, A. (2012). Sobre a objetividade prática do Design da Informação. $2^{\circ}$ GAMPI PLURAL, Univille, Joinville, SC.

Wanderley, R. G. (2015). Gestão do Conhecimento aplicada a comunicadaes produtivas artesanais. Tese (Doutorado). Departamento de pós graduação em design, Brasil: UNESP

Wanderley, R. G. (2015). Programas de Intervenções de design em comunidades artesanais:uma análise críca. Anais do $13^{\circ}$ Congresso Pesquisa \& Desenvolvimento em Design. Departamento de pós graduação em design, Brasil: UNESP

\section{Sobre o(a/s) autor(a/es)}

Renata GWanderley, Dra, UFPE, Brasil <renatagw@hotmail.com>

Cecilia da Rocha Pêssoa, Doutoranda, UFPE, Brasil <ceciliar.pessoa@gmail.com>

Camila Brito de Vasconcelos, Dra, UFPE, Brasil <camillacbv@hotmail.com> 